\title{
Théophile Gautier, Euvres complètes, section III, Théâtre et ballets
}

\section{Lise Sabourin}

\section{(2) OpenEdition}

10 Journals

\section{Édition électronique}

URL : https://journals.openedition.org/studifrancesi/26606

DOI : $10.4000 /$ studifrancesi.26606

ISSN : 2421-5856

Éditeur

Rosenberg \& Sellier

\section{Édition imprimée}

Date de publication : 1 avril 2007

Pagination : 201-202

ISSN : 0039-2944

\section{Référence électronique}

Lise Sabourin, «Théophile Gautier, EFuvres complètes, section III, Théâtre et ballets », Studi Francesi [En ligne], 151 (LI | I) | 2007, mis en ligne le 30 novembre 2015, consulté le 23 novembre 2021. URL : http:// journals.openedition.org/studifrancesi/26606 ; DOI : https://doi.org/10.4000/studifrancesi.26606

Ce document a été généré automatiquement le 23 novembre 2021.

\section{(c) $(1) \&$}

Studi Francesi è distribuita con Licenza Creative Commons Attribuzione - Non commerciale - Non opere derivate 4.0 Internazionale. 


\title{
Théophile Gautier, Euvres complètes, section III, Théâtre et ballets
}

\author{
Lise Sabourin
}

\section{RÉFÉRENCE}

THÉOPHILE GAUTIER, CEuvres complètes, section III, Théâtre et ballets, édition établie par Claudine LACOSTE-VEYSSEYRE et Hélène LAPLACE-CLAVERIE, avec la collaboration de Sarah MOMBERT, Paris, Champion, 2003, «Textes de littérature moderne et contemporaine», n. 61, pp. 1031.

1 On connaît la durée et la richesse des chroniques dramatiques de Gautier: c'est pourquoi ce volume de la section III de l'édition générale entreprise par Alain Montandon chez Champion porte à notre lecture, ainsi facilement accessible, les vingt et une pièces de théâtre et les douze ballets - dont six représentés - qui étaient «des rêves de poète pris au sérieux» pour Gautier. Outre une bibliographie, les habituels index de personnages fictifs, noms de personnes et de lieux, ce gros volume fournit en annexes (pp. 923-1009) la liste et souvent la citation des coupures de presse qui ont accueilli sa production scénique.

On utilisera avec bonheur les abondantes notes et variantes (pp. 695-919), mais aussi la riche introduction (pp.7-69) partagée entre Claudine Lacoste-Veysseyre, pour le théâtre, et Hélène Laplace-Claverie, quant aux ballets. Elle propose chronologie et analyse détaillée de tout le corpus, œuvre par œuvre, éclairant genèse, sources, circonstances de création qui permettent parfois de connaître les variantes intervenues sur les copies données aux acteurs et les modifications apportées après représentation. L'intérêt vif de Gautier pour tous les arts (par exemple l'orchestration orientale ou l'univers pictural de Goya), son sens de la collaboration avec les praticiens de la musique comme de la danse, sa large culture théâtrale (d'où ressort sa prédilection pour Shakespeare, Molière, Corneille et les dramaturges espagnols du Siècle d'or) confirment la puissance du genre théâtral dans son imaginaire qu'attestent, plus 
connus, ses romans et ses chroniques dramatiques, souvent sévères pour des œuvres décevantes esthétiquement, mais d'autant plus stimulantes pour sa propre créativité. Sa production théatrale et librettiste, le plus souvent novatrice et encline à expérimenter l'incarnation de ses fantasmes, mêle, parfois en parenté avec Musset, révolte contre toute rigidité, goût de la fantaisie et du pastiche, mais lutte toujours, au prix de quelques échecs, pour le triomphe de la littérature en tout domaine esthétique. Si le théâtre a été trop oblitéré, la postérité chorégraphique de Giselle, mais aussi de La Péri confirme qu'il a su ainsi rencontrer un public moderne. 